$\begin{array}{ll} & \text { Esta obra está sob o direito de } \\ & \begin{array}{l}\text { Licença Creative Commons } \\ \text { Atribuição 4.0 Internacional. }\end{array} \\ & \end{array}$

\title{
ATRAJETORIA DA PESQUISA EM EDUCAÇÃO NO BRASIL
}

José Silva de Menezes ${ }^{1}$

Dilson Cavalcante Tenório ${ }^{2}$

Betijane Soares de Barros ${ }^{3}$

\section{RESUMO}

Este artigo é uma revisão de literatura onde busca discutir a centralidade da pesquisa educacional, sua dimensão pública e articulações no mundo acadêmico. Faz- se uma trajetória da pesquisa educacional no Brasil e todo o seu desenvolvimento ao longo de anos. Tem como marco a criação do INEP (Instituto Nacional de Estudos e Pesquisas Educacionais), em 1938, ligado ao MEC, que vai apoiar pesquisas para dar subsídios às políticas educacionais. $\mathrm{O}$ outro marco é inaugurado com a criação do Centro Brasileiro e dos Centros Regionais de Pesquisa, em 1956, ligados ao INEP, que se encarregam da formação de recursos humanos para a pesquisa. $\mathrm{O}$ último momento é o da criação dos cursos de pós-graduação, na década de 70 , quando são dadas as condições para a institucionalização da pesquisa. Aponta o grande crescimento de trabalhos nos últimos 20 anos, acompanhado de muitas mudanças nos temas, enfoques, metodologias e contextos das pesquisas.

Palavras-chave: Pesquisa educacional. Políticas educacionais. Pós-Graduação.

\footnotetext{
1 jaelson_menezes@hotmail.com

2 dilsontenorio4@hotmail.com

3 bj.bs@hotmail.com
} 


\section{INTRODUÇÃO}

Para Duby (1998), o historiador tem o dever de não se fechar no passado e de refletir assiduamente sobre os problemas de seu tempo e de sua disciplina.

Este pensamento traduz a real situação em que vive a história da educação no Brasil, um campo pouco explorado pelos historiadores, onde devia ser uma área bastante explorada para que não houvesse problemas educacionais com os futuros professores, não só desta disciplina mas também em todas as outras. Conhecer e entender a história é uma questão prioritária de um educador.

$\mathrm{O}$ que se espera de um pesquisador de história da educação? Que conheça o seu ofício. O que se espera de um professor de História da Educação? Que ensine a pensar historicamente. Essa disciplina, se situa no quadro mais amplo das disciplinas que compõem a formação do professor nos cursos de pedagogia e nas outras licenciaturas e, obviamente, se articula (ou não) com as pesquisas nessa área. Geralmente pesquisadores de história da educação ensinam esta disciplina. Mas há aqueles que a ensinam sem serem pesquisadores da área ou mesmo praticantes da pesquisa (REIS E GONÇALVES, 2018).

Essa afirmação é feita com base na diversidade das instituições encarregadas da formação do professor e das condições para o exercício da pesquisa que revelam um espectro de situações, das mais favoráveis às mais improváveis (DUBY, 1998).

Se considerarmos, que a pesquisa e o ensino são serviços prestados com o objetivo de satisfazer às necessidades de alguém, é preciso identificar que demandas são feitas para esses serviços e quem as faz. Se pensamos na disciplina História da Educação como possibilidade de desenvolvimento da cidadania, temos uma demanda que provém da sociedade. Se pensamos na mesma disciplina com ênfase na aquisição de certos conhecimentos considerados imprescindíveis, temos uma demanda que provém da área disciplinar (DUBY, 1998).

Se pensamos na disciplina História da Educação como possibilidade dos estudantes apropriarem-se de um saber fazer que muda constantemente e que dá visibilidade à singularidade dos sujeitos, de sua história e da memória dos grupos aos quais pertencem, que pretende atender às necessidades do seu desenvolvimento pessoal temos uma demanda que provém das pessoas (REIS \& GONÇALVES, 2018). 


\section{MATERIAL E MÉTODOS}

Este estudo é uma pesquisa bibliográfica, onde a busca dos artigos a serem analisados foi realizada na base de dados BVS, Scielo e Google Acadêmico.

A escolha dessa base de dados justificou-se por ser gratuita e de livre

\section{RESULTADOS}

\section{A Trajetória da pesquisa em educação no Brasil}

Almeida (2010) comenta que a pesquisa educacional no Brasil teve seu início induzido por meio de ações governamentais, que buscavam subsídios para a formulação das políticas educacionais. Foi assim que em 1938 criouse o INEP (Instituto Nacional de Estudos e Pesquisas Educacionais), ligado ao MEC, onde a pesquisa foi entendida como recurso instrumental para a formulação e avaliação de ações oficiais no campo da educação escolar.

André (2006) enfatiza que a pesquisa era caracterizada pela leitura psicológica do processo de educação escolar, com forte influência dos estudos da psicologia do ensino e da aprendizagem e a criação de instrumentos de avaliação psicológica e pedagógica do aluno. As ideais pedagógicas eram marcadas pelo escolanovismo que, fundamentado na pedagogia científica, na biologia e na acesso e também pela crescente relevância que o Google vem adquirindo na difusão da produção acadêmica (DINIZ, 2012).

Foram utilizados no processo de busca os descritores, em português: educação básica, pesquisa e professor.

psicologia, defendia o ensino centrado no aluno e valorizava o aprender a aprender.

Em 1956, foram criados o Centro Brasileiro de Pesquisa Educacional e cinco Centros Regionais de Pesquisa, ligados então ao INEP, com a responsabilidade de formar pesquisadores para a área. Não desapareceu o caráter indutivo e instrumental das políticas governamentais orientadoras da pesquisa, mas mudaram-se os objetivos, que buscavam fazer o reconhecimento da sociedade brasileira e produzir dados capazes de sustentar uma política educacional voltada para o progresso econômico do país, levando em conta as diferenças regionais.

Gatti (2001, p. 66) aponta que “o Inep e seus centros constituíram-se em focos produtores e irradiadores de pesquisas e formação em métodos e técnicas de investigação científica em Educação, inclusive os de natureza experimental". De fato, há a passagem do enfoque psicopedagógico para os estudos de natureza sociológica, fazendo parte do 
universo da pesquisa a organização social da escola, as relações entre escola e sociedade. Pode-se destacar que as pesquisas em educação produziam, sob a responsabilidade de sociólogos e antropólogos, monografias e surveys.

Gouveia (1976) identificou as principais temáticas em estudo naquele momento: a mobilidade social, os processos de socialização regionais e comunitários, a correlação entre escolaridade e nível socioeconômico e a composição socioeconômica da clientela escolar.

Durante o período áureo da Ditadura Militar, as pesquisas educacionais foram reorientadas, desta vez incentivando a educação como investimento e seus custos, articulação direta com as diretrizes macro econômica.

Segundo Gatti (2001) a partir de meados da década de 60 começaram a ganhar fôlego e destaque os estudos de natureza econômica, com trabalhos sobre a educação como investimento, demanda profissional, formação de recursos humanos, técnicas programadas de ensino, etc. É o período em que se instalou o governo militar, redirecionando as perspectivas sócio-políticas do país. Passase a privilegiar os enfoques de planejamento, dos custos, da eficiência e das técnicas e tecnologias no ensino e ensino profissionalizante. A política científica passa a ser definida num contexto de macroplanejamento, direcionando os esforços e financiamentos no conjunto da política desenvolvimentista, não fugindo a pesquisa educacional em sua maior parte deste cenário e interesses.

Gouveia (1976) ainda afirma que lócus da pesquisa ainda não era a Universidade. A maior parte dos trabalhos realizados por professores universitários consistia, em esforços individuais relacionados a interesses intelectuais ou acadêmicos. A pesquisa era praticamente negligenciada nos orçamentos das universidades e em geral desempenhava papel secundário na carreira do professor universitário.

Só na década de 1970, ocorreu a implantação dos cursos de pós-graduação sob forma regulamentada, o que promoveu uma mudança significativa no campo das pesquisas educacionais. É o período da institucionalização da pesquisa em educação e, segundo Gatti (2000), foi isso que assegurou as condições do seu desenvolvimento e a formação de recursos humanos no país. O lócus da pesquisa passou a ser a Universidade e alguns centros especializados e houve uma mudança nos objetos e nos métodos da pesquisa. Gatti identificou os novos temas em estudo: currículos; avaliação de programas; caracterização de redes e recursos educativos; relações entre educação e trabalho; características de alunos, famílias 
e comunidade; nutrição e aprendizagem; validação e crítica de instrumentos de diagnóstico e de avaliação; estratégias de ensino - estudos que passaram a ser feitos a partir do uso de referenciais teóricos mais críticos e de instrumentos quantitativos mais sofisticados de análise. Porém, a autora aponta a permanência de problemas na qualidade dos trabalhos produzidos, como a pulverização de temas, o modismo e a fragilidade metodológica na abordagem e na análise dos problemas.

Essa fase histórica é marcada pela possibilidade de uma estrutura mais consolidada da pesquisa na área da Educação, o que se deu com a implantação do Parecer CFE no 977/65. Essa legislação trata a pós-graduação como lugar privilegiado de pesquisa no país, pois, de acordo com Cury (2005), a pós-graduação torna-se, assim, na universidade moderna, cúpula de estudos, sistema especial de cursos exigido pelas necessidades do treinamento avançado.

Com a implementação dos cursos de mestrado e doutorado no país há a intensificação dos programas de formação no exterior e absorção de pessoal e a formação de quadros para as universidades. Em paralelo, os Centros Regionais de Pesquisa em Educação (CRPE) do Inep são fechados, e são estabelecidos os investimentos destinados aos programas de pós-graduação nas universidades.
Nos anos de 1980/90, vivemos um forte crescimento das pesquisas educacionais, fruto da expansão do sistema de pós-graduação. As análises de André (2006) sobre esse período mostram que os pesquisadores passaram a desenvolver investigações a respeito dos processos educacionais, muitas vezes analisando a própria experiência, produzindo estudos sobre o contexto escolar específico, em que se destacam temáticas como o currículo, as interações sociais na escola, as formas de organização do trabalho pedagógico, a aprendizagem da leitura e da escrita, a disciplina e a avaliação.

Gatti (2000) considera que além da mudança de perspectiva e da variação temática, há também uma diversificação nas proposições metodológicas que colocam em questão a perspectiva tecnicista, anteriormente bastante forte. Passam a fazer parte do universo metodológico abordagens críticas como os estudos antropológicos e etnográficos, as pesquisas participantes, os estudos de caso, a pesquisa-ação e as análises de discurso, de narrativas, de histórias de vida. Amplia-se a interlocução com outras áreas de conhecimento, além da psicologia e da sociologia, como a antropologia, a história, a linguística, a filosofia, o que torna os entendimentos a respeito da problemática educativa mais amplos e sustentados por perspectivas que vão além das especificamente disciplinares. 
Para Gatti (2000), a propagação da metodologia de pesquisa-ação e da teoria do conflito no início dos anos 80, ao lado de um certo descrédito de que as soluções técnicas iriam resolver os problemas da educação brasileira, faz mudar o perfil da pesquisa educacional, abrindo espaço a abordagens críticas. Recorre-se não mais exclusivamente à psicologia ou à sociologia, mas à antropologia, à história, à linguística, à filosofia. Constata-se que para compreender e interpretar grande parte das questões e problemas da área de educação é preciso recorrer a enfoques multi/inter/transdisciplinares e a tratamentos multidimensionais. Pode-se afirmar que há um consenso sobre os limites que uma única perspectiva ou área de conhecimento apresentam para a devida exploração e para um conhecimento satisfatório dos problemas educacionais.

No final dos anos 80 e começo dos 90, a maior parte dos Programas de PósGraduação em Educação enfrentava uma crise gerada pelo modelo de áreas de concentração. Tal modelo exigia numerosas disciplinas obrigatórias, limitava ainda as disciplinas eletivas a áreas de domínio conexo e postergava a realização das dissertações e das teses para a fase final do curso, quando o tempo de integralização curricular do aluno estava se esgotando. As iniciativas para mudar essa estrutura centralizada nas áreas de concentração têm em comum: a) a prioridade dada à pesquisa e a diminuição do valor dado às disciplinas obrigatórias; b) a organização de grupos de estudos e pesquisas, que alteraram as condições institucionais da produção de dissertações e teses e c) a exigência no processo de seleção para os candidatos apresentarem projetos ajustados às linhas de pesquisa dos programas.

A discussão sobre os rumos da pósgraduação e da pesquisa nela produzida se faz mais intensa no começo dos anos 90: Cunha (1991) atribui ao Parecer 977/65 do CFE o arranjo para juntar um corpo docente diverso, prevendo a existência das áreas de concentração e das disciplinas de domínio conexo, precedidas por um grupo de disciplinas básicas, trazendo como elemento negativo o processo de composição inorgânica.

Ele ainda afirma que a heterogeneidade dos professores que ofereciam introduções gerais sobre diversas disciplinas, somada à também heterogeneidade dos estudantes, criou uma inorganicidade circular que afetou o nível acadêmico da pós-graduação e a qualidade da pesquisa por abordarem temas muitos diversos de forma improvisada, ajustando interesses conflitantes e justificando cargas horárias das denominadas disciplinas obrigatórias, mas sem conseguir tempo para a elaboração dos textos terminais das dissertações e teses. 
André (2006) afirma que se as duas últimas décadas também assistiram a uma mudança no contexto de produção dos trabalhos de pesquisa. Embora a grande maioria dos estudos continue sendo produzida nos programas de pós-graduação stricto sensu, as temáticas privilegiadas e as formas de desenvolvimentos desses estudos vêm sofrendo mudanças. Se nas décadas de 60-70 o interesse se localizava nas situações controladas de experimentação, do tipo laboratório, nas décadas de 80-90 o exame de situações "reais" do cotidiano da escola e da sala de aula é que constituíram as principais preocupações do pesquisador.

Se o papel do pesquisador era sobremaneira o de um sujeito de "fora", nos últimos anos tem havido uma grande valorização do olhar "de dentro", fazendo surgir muitos trabalhos em que se analisa a experiência do próprio pesquisador ou em que o pesquisador desenvolve a pesquisa em colaboração com os participantes (REIS \& GONÇALVES, 2018).

\section{Dificuldades das pesquisas em educação no Brasil}

Leite (2000) afirma que os limites e as possibilidades da pesquisa em educação no Brasil são pensados a partir de um determinado recorte: político-institucional, teórico-metodológico, qualidade e produtividade do trabalho científico, temas de investigação, entre outros. Entre as várias dificuldades indicadas, uma das mais frequentes é a fragilidade teóricometodológica dos trabalhos de investigação. Este tipo de desafio tem sido evidenciado através de diagnósticos e análises realizados sobre a produção científica em Educação.

Leite (2000) ainda expressa que a existência de tal crítica à pesquisa nos levou a uma preocupação com o aprofundamento do significado da noção de "teoria".

Marques (2001) uma das maiores dificuldades para os pesquisadores é o escrever. Marques (2001) ainda propõe que se deve escrever para pensar e não o contrário: pensar para escrever. Que escrever e coçar são atividades fáceis, necessitam apenas serem começadas e depois ficará difícil concluir. E que escrevendo se pode efetivamente produzir pesquisa.

Marques (2001) diz ainda que a escrita, nos meios acadêmicos, foi sendo tão encastelada que, aos poucos, pareceu tornar-se ação apenas de alguns, aqueles agraciados pela capacidade de produzir textos singulares, iluminados. Escrever é tão-somente produzir, sistematizar, criar. O próprio ato de redimensionar a primeira escrita, tornando-a uma segunda, mais elaborada, já é uma ação de pesquisa. Há algumas questões bem pontuais. Inicialmente, apresentação de uma pergunta para a qual os pesquisadores ainda não têm 
resposta e que será a orientadora de todas as outras etapas.

Outra questão para Marques (2001) é a descrição metodológica. A descrição das escolhas metodológicas não só estabelece os caminhos a percorrer e como percorrêlos, como estabelece parâmetros para a ação do pesquisador e a delimitação do material teórico. E, ainda, a confiabilidade das respostas obtidas e o grau de cientificidade destas. Importante destacar a relação entre estas questões e o referencial teórico dos pesquisadores. É através do referencial teórico que a pesquisadora, o pesquisador enxerga o mundo, atribui sentidos, escolhe. Portanto, é fundamental conhecer-se ao ponto de saber quais são as tendências, as crenças, as possibilidades de uma abordagem científica em acordo com suas escolhas teóricas, evitando, assim, a superficialidade.

Orientar o trajeto da investigação, elaborar conceitos e categorias, oferecer elementos de análise da realidade, indicar possibilidades do real e apontar a provisoriedade do conhecido são tarefas teóricas que, de modo nenhum, estão restritas às atividades de investigação da realidade da natureza. A aproximação do real cultural também exige a produção destes elementos capazes de indicar as pistas da investigação, a elaboração de conceitos e categorias, a sugestão de aspectos fundamentais para exame desse real, o horizonte das alternativas para o cotidiano do homem e a identificação dos limites explicativos do conhecimento construído (REIS \& GONÇALVES, 2018).

Ferreira (2009) diz que um último aspecto considerado como dificuldade diz respeito ao financiamento da pesquisa. No Brasil, o Estado investe cada vez menos na educação e as políticas públicas denotam uma preocupação com o Ensino Fundamental como etapa de escolarização que formará mão-de-obra (nem sequer corpo de obra) barata. O ensino superior é tratado com descaso ou mediante propostas polêmicas, como cotas para afrodescendentes e indígenas, privatização e avaliação.

Ferreira (2009) diz que se se pensava que com o surgimento de instituições de pesquisa, expansão do CNPq, da Financiadora de Estudos e Projetos (Finep) e das fundações estaduais, haveria uma diversidade de verbas para a pesquisa científica, o que se comprovou, houve também uma explosão de publicações e, como dizem diversos autores, a qualidade não correspondeu aos recursos disponíveis. Paralelamente, a associação do ensino com a pesquisa levou à necessidade de fazer currículo. Dessa forma, é comum encontrar trabalhos de professores universitários técnica e metodologicamente muito bem elaborados, mas que pouco acrescentam à produção do 
conhecimento. Publicados, portanto, unicamente para servir na obtenção de títulos.

\section{CONCLUSÃO}

No Brasil, o surgimento da disciplina História da educação está ligado à Escola normal, que foi criada em 1835, mas só tem seu avanço no século XIX com a criação do curso de pedagogia em 1939 é com ela a obrigatoriedade do desta disciplina, e a ampliação com o curso de pós graduação.

Ministrada apenas na área de educação e optativa para outros programas, nem mesmo os cursos de pós graduação em história ofertam essa disciplina.

Como disciplina formativa, a disciplina de História da Educação vem perdendo espaço nos cursos de formação para professores de ensino fundamental I e II e de ensino médio. Fala-se que essa crise decorre do fato de que os pesquisadores da área não são os mesmos que ministram a disciplina nos cursos de graduação.

A disciplina deveria se aproximar e dialogar com os outros componentes do currículo com a finalidade de contribuir mais efetivamente para a formação dos professores. Um passo importante é trazer a atividade de pesquisa que tanto contribui para o campo da História da Educação para a graduação, traduzida em incentivos à

iniciação científica e ao estabelecimento de uma estreita relação entre a graduação e pós-graduação Lato e Stricto Sensu.

Há um grande avanço nas pesquisas relacionadas a História da Educação, porém estão concentradas nas regiões Sul, Sudeste e em seguida na região Nordeste, Centro Oeste e Norte. Há também uma diversidade de temas e abordagens teóricometodológica, impedindo assim que se tenha uma historiografia e uma teoria histórica diferenciada da educação com variável social.

Outro fator é que há um grande desconhecimento por parte do historiador de produções da área de História da Educação, fato este que empobrece as possibilidades de interpretação do objeto de estudo.

As

novas

tendências historiográficas, ou seja, a relação entre História Cultural e História da Educação, promove o alagamento das possibilidades investigativas do historiador, onde a História Cultural os ajudara a compreender os diferentes processos educativos $\mathrm{e}$ escolares.

Carvalho (2005) enfatiza que nesse processo de reconfiguração, a História da Educação se multiplica em uma pluralidade 
de domínios - história das disciplinas escolares, história da profissão docente, história do currículo, história do livro didático etc. Repartindo-se nesses domínios, a história da educação desloca a demarcação entre história das ideias e história dos sistemas educacionais que a vinha configurando como campo de pesquisa.

A história da educação não se libertou ainda de seu antigo lastro filosófico mesmo funcionando hoje, em geral, nos departamentos de teoria e história da educação, o que implica o fato de que seus pesquisadores e docentes são, na maioria das vezes, universitários sem formação histórica específica.

\section{REFERENCIAS}

ANDRÉ, M. A pesquisa sobre Formação de professores no Brasil-1990-1998. In: CANDAU, Vera M. (Org.). Ensinare aprender: sujeitos, saberes e pesquisa. Rio de Janeiro,RJ: DP\&A, 2000.

CARVALHO, Marta Maria Chagas de. Considerações sobre o ensino da História da Educação no Brasil. In: História da Educação em Perspectiva: ensino, pesquisa, produção e novas investigações. São Paulo, Editora. Autores Associados, 2005.

A configuração da

Historiografia Educacional Brasileira: in: Historiografia Brasileira em Perspectiva. São Paulo, Editora Contexto, 2003.

CUNHA, L.A.C. Os (des)caminhos da pesquisa na pós-graduação em educação.
Quanto aos pesquisadores em História da Educação e suas produções na área, pode-se afirmar que é pouco expressiva e que há uma grande ausência destes pesquisadores, apesar de já haver um grande avanço, especificamente em publicações internacionais.

A História da Educação deve principalmente propiciar a interpretação e avaliação dos fatos e movimentos educacionais, dentro dos movimentos sociais mais amplos como parte de uma realidade concreta. Como uma área de saber, deverá contribuir na (re)construção e (re)interpretação de muitos aspectos da História da Educação no país.

In: SEMINÁRIO SOBRE A PRODUÇÃO

CIENTÍFICA NOS PROGRAMAS DE PÓSGRADUAÇÃO EM EDUCAÇÃO. Brasília, MEC/CAPES, 1979. p. 3-15.

CUNHA, L.A.C. Pós-graduação: ponto de inflexão? Cadernos de Pesquisa, n. 77, p. 63-80, maio, 1991.

CURY, C. R. J. Quadragésimo ano do parecer CFE $n^{\circ}$ 977/65. Revista Brasileira de Educação: sobre os 40 anos da PósGraduação em Educação, n. 30, set/out/nov/dez, 2005.

Gouveia, A. Joly. Pesquisa educacional no Brasil. Cadernos de Pesquisa, n.1, pp.1-48, 1971.

. Pesquisa em educação no Brasil: de 1970 para cá. Cadernos de Pesquisa, n.19, pp.75-79, 1976. 